\title{
Is Hypo fractionated Stereotactic Radiotherapy (FSRT) Effective for all Intracranial Meningiomas?
}

\author{
Chandana Sanjee, Suneetha Narsiyappa, Vijay Bhaskar, GurunathKilara, G Lohith*, Ramesh Bilimagga, Somrat \\ Bhattacharjee, Kumaraswamy, Vikram Maiya and MS Belliappa
}

Radiation Oncologist, Healthcare Global Enterprises Limited, India

Submission: July 19, 2017; Published: July 28, 2017

"Correspondence Address: G Lohith, Consultant Radiation Oncologist, Healthcare Global Enterprises Limited, Bangalore, India, Email: lampard_buddyy@hotmail.com

\begin{abstract}
Background: The maximum Meningioma tumour volume which can be treated by Hypo fractionated Stereotactic Radiotherapy/ Fractionated Stereotactic Radiotherapy (FSRT) is unknown.

Objective: A retrospective review of patients with meningioma treated by Hypo fractionated Stereotactic Radiotherapy.

Methods: 40Meningiomas were treated, either as a primary treatment or after surgery. FSRT was delivered to a median marginal dose of 21.3Gy (Range 9-27.3Gy) in 2 to 5 fractions targeting a median tumour volume of $21 \mathrm{~cm} 3(3-144 \mathrm{~cm} 3)$.

Results: After a median follow-up time of 36 months (Range 12-78 months), Survival and follow up data was available for 27 patients The overall survival was $85 \%$, Progression free survival was $78 \%$. Tumour volume was an independent prognostic factor. A volume of $<30 \mathrm{~cm} 3$ had a progression free survival was of $90 \%$ and $>30 \mathrm{~cm} 3$ had $42.8 \%$ (p 0.024).There were 3 cases of radiation toxicity.

Conclusion: Meningioma of volume $<30 \mathrm{~cm} 3$ can be effectively treated by Hypo fractionated Stereotactic Radiotherapy with an acceptable toxicity profile.
\end{abstract}

Abbreviations: FSRT: Fractionated Stereotactic Radiotherapy; GTV: Gross Tumour Volume; SRS: Stereotactic Radio-Surgery; CDMS: Cyber knife Data Management System

\section{Introduction}

Meningioma accounts for more than one third of all primary Central Nervous System tumours. Meningioma has a spectrum of presentation from being asymptomatic to having neurological deficits which can be life threatening at times.. Similarly even the management of meningioma ranges from observation $[1,2]$ to multimodality treatment which mainly includes surgery and radiotherapy [3-5]. Although Surgery is considered the gold standard treatment for meningioma, it is not always accessible and even if accessible it is not always possible to achieve a gross total resection; hence adjuvant radiotherapy is used to improve local control rates $[6,7]$. In conventional radiotherapy techniques, Gross Tumour Volume is contoured after co-registration with MRI. A margin of $0-2 \mathrm{~cm}$ is given for CTV depending on the grade of Meningioma and treated to a dose of 54-60Gy at 1.8-2Gy per fraction often resulting in a large volume of normal brain receiving radiation. The other alternative is Hypo fractionated Stereotactic Radiotherapy/Stereotactic (SRS), in which higher doses of radiation is delivered per fraction with high conformity.
In this study we aim to study the role of Hypo fractionated Stereotactic Radiotherapy in treatment of meningioma as a primary treatment and as an adjuvant to surgery in Meningioma.

\section{Cyber knife based Hypo fractionated Stereotactic Radiotherapy}

Conventional Radiotherapy techniques have been associated with treatment of increased volume of normal brain. Hence, advances in radiotherapy delivery techniques and imaging technologies have led to the invention of multiple radiation delivery systems. Cyber knife is a robotic stereotactic radiosurgery delivery system which uses a 6MV miniaturised linear accelerator mounted on the robotic arm. This system uses a noninvasive patient immobilization system and real time tracking system, hence can be used in medically inoperable and surgically unrespectable meningioma with.

The tracking system consists of two orthogonally mounted $\mathrm{kV}$ x-ray on the ceiling and corresponding amorphous silica $\mathrm{x}$-ray 


\section{Cancer Therapy \& Oncology International Journal}

detectors mounted on the floor. The images obtained through these detectors are compared with the digitally reconstructed images from the library of CT scan images taken during the simulation. The software used for tracking the head and neck site treatment is called 6D Skull software, named because, this software takes into account all the movements in $\mathrm{X}, \mathrm{Y}, \mathrm{Z}$ and also the three rotational movements. The robotic arm has five moving joints which in combination produce movement in six axes for the linear accelerator head, making treatment planning easy to treat any type of target. Cyber knife uses Multiplan software for treatment planning and Cyber knife Data Management System (CDMS) for handling the data between the planning and treatment delivery systems. Cyber knife has an ability to achieve good conformity and high Homogeneity index $[8,9]$.

\section{Meningioma and Hypo fractionated Stereotactic Radiotherapy}

Stereotactic Radio-surgery (SRS) is defined as delivery of a high dose of up to maximum of $15 \mathrm{~Gy}$ in a single session and is indicated only if the tumour volume is less than $10-15 \mathrm{~cm} 3$ with a minimal distance of optic apparatus of between 2-4mm [10,11]; thereby not all meningioma are eligible for SRS. Meningioma has an alpha/beta ratio of 3.76, hence sensitive to high dose per fraction [12]. In these patients Hypo fractionated Stereotactic Radiotherapy also known as Fractionated Stereotactic Radio surgery can be considered. There is no clear consensus as to the volume which is should be considered maximum for Hypo fractionated Stereotactic Radiotherapy.

\section{Methods and Materials}

Table 1: Patient Characteristics.

\begin{tabular}{|c|c|}
\hline \multicolumn{2}{|c|}{ Age at treatment (yrs.) } \\
\hline Median & 52 \\
\hline \multicolumn{2}{|c|}{ Sex (Number) } \\
\hline Female & 22 \\
\hline Male & 17 \\
\hline Past Radiation history for other conditions & 2 \\
\hline \multicolumn{2}{|c|}{ Type of Treatment } \\
\hline Primary(No previous surgery) & $11(27.5 \%)$ \\
\hline Adjuvant for residue(Within 90 days of surgery) & $7(17.5 \%)$ \\
\hline Recurrence(After 90 daysof Surgery/RT/SRT) & $22(55 \%)$ \\
\hline Post-Surgery & 17 \\
\hline Post Surgery+Conventional fractionation EBRT & 3 \\
\hline Post HSRT & 1 \\
\hline Number of cases to received HSRT as boost post EBRT & 1 \\
\hline \multicolumn{2}{|c|}{ Grade of Meningioma } \\
\hline Grade 1 & 16 \\
\hline Grade 2 & 8 \\
\hline Grade 3 & 1 \\
\hline NA & 4 \\
\hline
\end{tabular}

Patient data were obtained from a prospectively maintained database of patients treated by use of the Cyber Knife Robotic Radio surgical System (Accuray, Sunnyvale, California) at the Health Care Global Enterprises, Bangalore. Data of 39 patients and 40meningiomas from September 2009-January 2016 were available. Follow up data, Dose and tumour volume information was available for 27patients. Patient characteristics are in (Table 1). Majority of patients presented with complaints of Headache, Seizures, Motor weakness and Progressive decrease in vision.

Twenty two women and seventeen men received Stereotactic radiation with a median age of 52 years. Two of these patients had past history of cranial irradiation (oligodendroglioma and medulloblastoma) .Patients were referred for radiotherapy if the tumour was inaccessible for surgery (Primary $n=12$ ) or as adjuvant Post surgery for residue (adjuvant treatment $\mathrm{n}=7$ ). It was considered adjuvant treatment if patient received radiation within 90 days of surgery or recurrence $(n=22)$ if received radiation after 90 days, either post-surgery $(n=17)$ or post-surgery+EBRT $(n=3)$ or Previous Stereotactic radiation $(\mathrm{n}=1)$. Among the 22 recurrence patients 4 patients were post radiation recurrence who was considered for re-irradiation. The four cases had received conventional fraction radiation 4,5 , and 7 years before this treatment, one case received FSRT as boost post Conventional Radiotherapy and one case had received FSRT 5 years ago (Table 1 ). 


\section{Cancer Therapy \& Oncology International Journal}

\section{Radiotherapy Technique}

Table 2: Treatment Characteristics.

\begin{tabular}{|c|c|}
\hline \multicolumn{1}{|c|}{ Number of lesions treated } & 1 \\
\hline Median & 40 \\
\hline \multicolumn{2}{|c|}{ Number of Fractions } \\
\hline 2 & 1 \\
\hline 3 & 15 \\
\hline 4 & 1 \\
\hline 5 & 23 \\
\hline Median Target Volume( cm3 ) & $21.8 \mathrm{~cm} 3$ (Range 3-144 cm3 \\
\hline Median Marginal Prescription Dose & $21.3 \mathrm{~Gy}$ (Range 9-27.3Gy) \\
\hline Median Prescription Isodose line & 80 \%( Range 67-91\%) \\
\hline Number of cases $<35 \mathrm{~cm} 3$ & 20 \\
\hline Number of cases with Progressive disease & 2 \\
\hline Number of cases $>35 \mathrm{~cm} 3$ & 7 \\
\hline Number of cases with Progressive disease & 5 \\
\hline
\end{tabular}

The Cyber Knife Robotic Radio surgical System (Accuray, Sunnyvale, California) was used to deliver the Hypo fractionated Stereotactic radiotherapy treatments. A high- resolution thinslice $(1.25 \mathrm{~mm}$ ) computed tomogram was obtained which is coregistered and fused with an MRI of slice thickness of $1.25 \mathrm{~mm}$ to assist target delineation. The neuroradiologist, radiation oncologist review the MRI and delineate the Gross Tumour Volume (GTV). No margin was given as Clinical Target Volume (CTV) and a margin of $1-2 \mathrm{~mm}$ was given to account for fusion error and contoured as Planning Target Volume (PTV). Iterative treatment plan was obtained using Cyber Knife nonisocentric inverse treatment planning software.

\section{Radio surgery Dose and Fractionation}

The prescribed dose and fractionation schedule were based on the size of the lesion, proximity of the lesion to nearby critical structures, and dose of prior radiation. Common dosage schedules used were 24-32.5Gy/2-5\# (EQD2 44Gy-54Gy). Treatment characteristics are listed in (Table 2). FSRT was delivered to a median marginal dose of 21.3 (range, 9-27.3Gy) prescribed to the median $80 \%$ isodose line (range, 67-91\%), median tumour volume was21.8 cm3 (Range 3-144 cm3). FSRT was delivered in 2 to 5 fractions (Median 5).

\section{Follow-up}

MRI was done on follow up visits. Of the treated 40meningioma, follow up imaging was available for 30 cases. Twenty One cases had Stable disease (As per RECIST). Even though the size of the lesion was stable, there was relief from complaints of the patient.

\section{Toxicity}

On follow up a Cerebellopontine angle Meningioma post
FSRT had persistent headache and hence underwent Surgery another Tentorial Meningioma developed Trigeminal neuralgia 4-5 months after treatment and a Frontal lobe meningioma received Anti edge a measures post treatment due to treatment related oedema.

\section{Statistical Analysis}

The collected data was analysed with Statistical Package for Social Sciences for Windows, Version 16.0, (SPSS Inc., Chicago, IL, USA). To describe about the data Descriptive statistics, frequency analysis and percentage analysis were used for Categorical variables and the mean, median\& S.D was used for continuous variables. To find the significant difference between two Independent groups Fischers exact test was used if any of the expected count was $<5$. Unpaired sample t-test (two tailed) was used for normal data and Mann-Whitney U test was used for skewed data. To find the significance in categorical data, Chi-Square test was used. Patient was considered progression if there was radiological evidence of $>20 \%$ increase in the longest diameter of lesion (not including oedema). Overall Survival is the percentages of patients who survive from the end to FSRT to the last follow up. Progression Free Survival is the percentage of patients who neither progress nor die from the end of SRT to last follow up.

\section{Results}

After a median follow-up time of 36 months (Range 12-78), Survival and follow up data was available for 27 patients. The overall survival was $85 \%$, Progression free survival was $78 \%$. In Univariate analysis tumour volume was an independent prognostic factor. A volume of $<30 \mathrm{~cm} 3$ had a progression free survival was of $90 \%$ and $>30 \mathrm{~cm} 3$ had a PFS of $42.8 \%$ (p 0.024 ). There were 3 cases of radiation toxicity (Tables $2 \& 3$ ) (Figure 1). 


\section{Cancer Therapy \& Oncology International Journal}

Table 3: Summary of all cases treated by Hypo fractionated Stereotactic Radiotherapy.

\begin{tabular}{|c|c|c|c|c|c|c|}
\hline Sl & Location Treated & Surgery & $\begin{array}{c}\text { Primary(P) } \\
\text { /Adjuvant(A) } \\
\text { /Recurrent(R) }\end{array}$ & Total Dose & $\begin{array}{c}\text { Volume } \\
\mathbf{c m}^{3}\end{array}$ & Local Outcome \\
\hline 1 & Orbital & No surgery & $\mathrm{P}$ & 21 & 38.4 & $\mathrm{PD}$ \\
\hline 2 & Temporal & No surgery & $\mathrm{P}$ & 21 & 6.3 & Died due to GIST \\
\hline 3 & Para-Saggital & $\begin{array}{l}\text { Craniotomy decompression of tumor } \\
\text { and cranioplasty }\end{array}$ & $\mathrm{R}$ & 24 & 22.7 & NA \\
\hline 4 & $\begin{array}{l}\text { Recurrent } \\
\text { Meningioma }\end{array}$ & Craniotomy+ Excision & $\mathrm{R}$ & 30 & NA & PD \\
\hline 5 & Foramen Magnum & Decompression & $\mathrm{R}$ & 20 & NA & SD \\
\hline 6 & Frontal & Frontal craniotomy+ Excision & A & 21 & NA & SD \\
\hline 7 & Pterional & Pterional craniotomy + Excision & $\mathrm{R}$ & 35 & NA & PD \\
\hline 8 & R Sphenoid Wing & No surgery & $\mathrm{P}$ & 25 & 8.2 & SD \\
\hline 9 & Basi-Sphenoidal & Basisphenoidal meningioma excision & $\mathrm{R}$ & 27.5 & 27.8 & NA \\
\hline 10 & Para Saggital & Fronto parietal parasaggital craniotomy & A & 24 & 15.1 & SD \\
\hline 11 & CP Angle Tumor & Not done & $\mathrm{P}$ & 24 & NA & SD \\
\hline 12 & Parasellar & Pterional craniotomy + Excision & $\mathrm{R}$ & 30 & 14.7 & SD \\
\hline 13 & Parietal & Fronto parietal craniotomy + Excision & A & 24 & 14.5 & SD \\
\hline 14 & $\begin{array}{l}\text { L Para Sellar } \\
\text { Meningioma }\end{array}$ & No surgery & $\mathrm{P}$ & 32.5 & NA & SD \\
\hline 15 & $\begin{array}{c}\text { Parietal } \\
\text { Parasaggital }\end{array}$ & Craniotomy and Excision & $\mathrm{R}$ & 18 & 30 & $\begin{array}{l}\text { PD, Died due to } \\
\text { seizures }\end{array}$ \\
\hline 16 & Spheno-Petro Clival & Suboccipitalcraniectomty+ Excision & A & 21 & & NA \\
\hline 17 & CP Angle & No surgery & $\mathrm{P}$ & 30 & 6.4 & SD \\
\hline 18 & $\begin{array}{l}\text { Cavernous Sinus/ } \\
\text { Parasellar }\end{array}$ & No surgery & $P$ & 32.5 & 24.4 & SD \\
\hline 19 & $\begin{array}{l}\text { Middle Cranial } \\
\text { Fossa }\end{array}$ & Craniectomy+ Decompression & A & 30 & 101 & $\begin{array}{l}\text { PD, Died due to } \\
\text { meningioma }\end{array}$ \\
\hline 20 & CP Angle & $\begin{array}{l}\text { Retromastoidsuboccipitalcraniectomy } \\
\text { and total excision }\end{array}$ & $\mathrm{R}$ & 24 & 7.3 & SD \\
\hline 21 & Parasellar & No surgery & $\mathrm{P}$ & 25 & 59.4 & SD \\
\hline 22 & Frontal Lobe & No surgery & $\mathrm{P}$ & 25 & NA & SD \\
\hline 23 & Parietal & Parietal craniectomy + Excision & $\mathrm{R}$ & 28 & 36.7 & $\begin{array}{l}\text { PD, Died due to } \\
\text { meningioma }\end{array}$ \\
\hline 24 & FrontoParasaggital & Frontal craniotomy+Excision & $\mathrm{R}$ & 25 & 11.2 & SD \\
\hline 25 & Orbital & No surgery & R (After SRT) & 30 & 125.9 & NA \\
\hline 26 & Foramen Magnum & Craniotomy + Excision & $\mathrm{R}$ & 32.5 & 12 & SD \\
\hline 27 & $\begin{array}{l}\text { Spheno Cavernous } \\
\text { Petro Clival }\end{array}$ & Fronto-temporo craniotomy & $\mathrm{R}$ & 30 & 16.7 & SD \\
\hline 28 & Sphenoid Wing & Craniotomy + Excision & $\mathrm{R}$ & 30 & 144.9 & SD \\
\hline 29 & Optic N Sheath & No surgery & $\mathrm{P}$ & 30 & 3.2 & SD \\
\hline 30 & Frontoparietal & $\begin{array}{l}\text { Craniotomy in Nov } 2010 \text { and } \\
\text { recraniotomy on } 25.04 .12\end{array}$ & $\mathrm{R}$ & 24 & 20.8 & $\begin{array}{l}\text { PD, Died due to } \\
\text { disease }\end{array}$ \\
\hline 31 & Olfactory Groove & Craniotomy & $\mathrm{R}$ & 30 & 7.4 & SD \\
\hline 32 & Cavernous Sinus & Fronto-orbito-temporal craniotomy & $\mathrm{R}$ & 25 & 23 & SD \\
\hline 33 & Lat Ventricle & $\begin{array}{l}\text { Fronto-parietal parasaggital } \\
\text { craniotomy }\end{array}$ & $\mathrm{R}$ & 25.5 & 3 & SD \\
\hline 34 & CP Angle & $\begin{array}{l}\text { Retro mastoid sub occipital craniotomy } \\
\text { with excision of L CP SOL }\end{array}$ & $\mathrm{R}$ & 30 & 16.9 & SD \\
\hline
\end{tabular}




\section{Cancer Therapy \& Oncology International Journal}

\begin{tabular}{|c|c|c|c|c|c|c|}
\hline 35 & $\begin{array}{c}\text { Sphenoid Ridge } \\
\text { and , High Parietal } \\
\text { Diploic }\end{array}$ & Crianiotomy and excision & $\mathrm{R}$ & 12 & 27.9 & SD \\
\hline 36 & Frontal & Crianiotomy and excision & $\mathrm{R}$ & 32.5 & 27.1 & SD \\
\hline 37 & $\begin{array}{c}\text { High Parietal Para } \\
\text { Saggital }\end{array}$ & Front parietal craniotomy & $\mathrm{R}$ & 21 & 66.1 & PD but alive \\
\hline 38 & Clival & Excision & $\mathrm{R}$ & 26 & & NA \\
\hline 39 & $\mathrm{CP}$ angle & Craniotomy & A & 24 & 78.2 & SD \\
\hline 40 & Tentorial & Not done & $\mathrm{P}$ & 24 & NA & NA \\
\hline
\end{tabular}

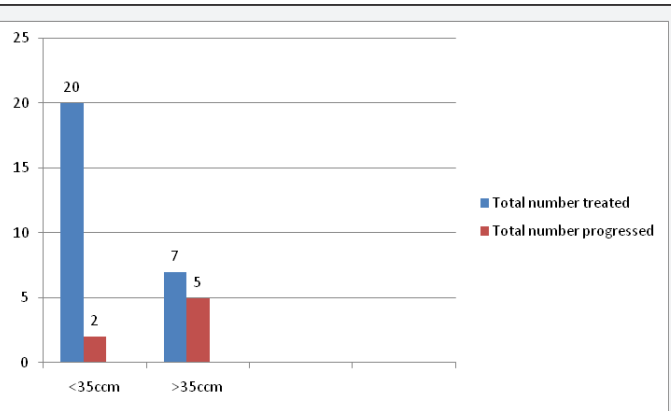

Figure 1: A volume of $<30 \mathrm{~cm} 3$ had a progression free survival was of $90 \%$ and $>30 \mathrm{~cm} 3$ had a PFS of $42.8 \%$ ( $p 0.024$ ).

\section{Discussion}

Achieving high therapeutic ratio in meningioma is always challenging, as majority of lesions are benign and achieving Gross total resection is difficult. Conventional radiotherapy has been advocated as an adjuvant to surgery. Treatment with Hypo fractionated Stereotactic Radiotherapy has better conformity and shorter treatment time compared to conventional radiotherapy. Encouraging results have been obtained by the multiple studies have studied the role of SRS and Hypo fractionated Stereotactic Radiotherapy in Meningioma [13-15]. But no clear consensus regarding the maximum volume for consideration of Hypo fractionated Stereotactic Radiotherapy has been obtained. This study suggests that any meningioma, either primary, postsurgery or recurrence can be treated by Hypo fractionated Stereotactic Radiotherapy if the volume is lesser than $30 \mathrm{~cm} 3$.

Kondziolka D et al. [13] analyzed 203 parasaggitalmeningioma's treated by gamma knife and concluded that the local control was $100 \%$, if the volume was $<7.5 \mathrm{~cm} 3$. Federico Colombo et al. [14] analyzed 199 benignmeningioma's treated using Cybeknife based SRS and HSRT. After a mean follow up of 30 months, the local control was $96.5 \%$. Lee et al. [15] analyzed a series of 159 patients with cavernous sinus meningiomas treated with gamma knife radiosurgery showing local control of $96 \%$ if they were treated primarily by Gamma knife without previous surgery and local control was $93 \%$. He also suggested that if the volume $<15 \mathrm{~cm} 3$ this treatment is effective.

\section{Conclusion}

SRS and FSRT are effective and safe treatment modality for local control of meningioma with acceptable toxicity. Hypo fractionated Stereotactic Radiotherapy (FSRT) can be considered and is effective when the volume of meningiomas is less than 30 cm3 volume.

\section{References}

1. Go RS, Taylor BV, Kimmel DW (1998) The natural history of asymptomatic meningiomas in Olmsted County, Minnesota. Neurology 51(6): 1718-1720.

2. Nakamura M, Roser F, Michel J, Jacobs C, Samii M, et al. (2003) The natural history of incidental meningiomas Neurosurgery 53(1): 62-70.

3. Rogers L, Barani I, Chamberlain M, Kaley TJ, McDermott M, et al. (2015) Meningiomas: knowledge base, treatment outcomes, and uncertainties. A RANO review.J Neurosurg 122(1): 4-23.

4. Wang C, Kaprealian TB, Suh JH, Kubicky CD, Ciporen JN, et al. (2017) Overall survival benefit associated with adjuvant radiotherapy in WHO grade II meningioma. NeuroOncol.

5. Aizer AA, Arvold ND, Catalano P, Claus EB, Golby AJ, et al. (2014) Adjuvant radiation therapy, local recurrence, and the need for salvage therapy in atypical meningioma. NeuroOncol 16(11): 1547-1553.

6. Alkemade H Van, Leau M De, Dieleman EMT, Kardaun JWPF, Os R Van, et al. (2012) problems in benign meningioma 14(5): 658-666.

7. Kaur G, Sayegh ET, Larson A, Bloch O, Madden M, et al. (2014) NeuroOncology 16: 628-636.

8. Kurup G (2010) CyberKnife: A new paradigm in radiotherapy. Journal of Medical Physics/ Association of Medical Physicists of India 35(2): 63-64.

9. Joseph B, Supe SS, Ramachandra A (2010) Cyberknife: A double edged sword? Reports of Practical Oncology and Radiotherapy 15(4): 93-97.

10. Subach BR, Lunsford LD, Kondziolka D, Maitz AH, Flickinger JC, et al. (1998) Management of petroclivalmeningiomas by stereotactic radiosurgery. Neurosurgery 42: 437-443; discussion 443-435.

11. Kondziolka D, Flickinger JC, Perez B (1998) Judicious resection and/or radio surgery for parasagittal meningiomas: outcomes from a multicenter review. Gamma Knife Meningioma Study Group Neurosurgery 43(3): 405-413; discussion 413-414.

12. Vernimmen FJ, Slabbert JP (2010) Assessment of the alpha/beta ratios for arteriovenous malformations, meningiomas, acoustic neuromas, and the optic chiasma. Int J Radiat Biol 86(6): 486-498.

13. Kondziolka D, Flickinger JC, Perez B (1998) Judicious resection and/or radiosurgery for parasagittal meningiomas: outcomes from a multicenter review. Gamma Knife Meningioma Study Group. Neurosurgery 43(3): 405-413.

14. Colombo F, Casentini L, Cavedon C, Scalchi P, Cora S, et al. (2009) Cyberknife radiosurgery for benign meningiomas: short-term results in 199 patients. 64(2 Suppl): A7-13.

15. Lee J, Stippler M, Niranjan A, Kondziolka D, Flickinger J, et al. (2005) Gamma Knife Radiosurgery for Cavernous Sinus Meningiomas. Radiosurgery 6: 118-130. 
This work is licensed under Creative Commons Attribution 4.0 License DOI: $10.19080 /$ CTOIJ.2017.06.555685

\section{Your next submission with Juniper Publishers} will reach you the below assets

- Quality Editorial service

- Swift Peer Review

- Reprints availability

- E-prints Service

- Manuscript Podcast for convenient understanding

- Global attainment for your research

- Manuscript accessibility in different formats

( Pdf, E-pub, Full Text, Audio)

- Unceasing customer service

Track the below URL for one-step submission https://juniperpublishers.com/online-submission.php 